\title{
Endoscopic Ultrasound-Guided Biliary Drainage for Unresectable Hilar Malignant Biliary Obstruction
}

\author{
Yousuke Nakai ${ }^{1}$, Hirofumi Kogure ${ }^{1}$, Hiroyuki Isayama ${ }^{1,2}$ and Kazuhiko Koike ${ }^{1}$ \\ Department of Gastroenterology, Graduate School of Medicine, ${ }^{1}$ The University of Tokyo, ${ }^{2}$ Juntendo University, Tokyo, Japan
}

Endoscopic transpapillary biliary drainage is the current standard of care for unresectable hilar malignant biliary obstruction (MBO) and bilateral metal stent placement is shown to have longer patency. However, technical and clinical failure is possible and percutaneous transhepatic biliary drainage (PTBD) is sometimes necessary. Endoscopic ultrasound-guided biliary drainage (EUS-BD) is increasingly being reported as an alternative rescue procedure to PTBD. EUS-BD has a potential advantage of not traversing the biliary stricture and internal drainage can be completed in a single session. Some approaches to bilateral biliary drainage for hilar MBO under EUSguidance include a bridging method, hepaticoduodenostomy, and a combination of EUS-BD and transpapillary biliary drainage. The aim of this review is to summarize data on EUS-BD for hilar MBO and to clarify its advantages over the conventional approaches such as endoscopic transpapillary biliary drainage and PTBD. Clin Endosc 2019;52:220-225

Key Words: Biliary drainage; Endosonography; Hilar biliary obstruction; Neoplasms

\section{INTRODUCTION}

Patients with hilar malignant biliary obstruction (MBO) often present at an unresectable stage. Endoscopic transpapillary biliary drainage (EBD) is the current standard of care to relieve jaundice. Multiple metallic stent (MS) placement is often performed but is technically demanding and percutaneous transhepatic biliary drainage (PTBD) is sometimes needed after technical or clinical failure by endoscopic approach. ${ }^{1}$

Endoscopic ultrasound-guided biliary drainage (EUS$\mathrm{BD})$ for $\mathrm{MBO}$ is being increasingly reported but is mostly performed for distal MBO and only by experts. ${ }^{2,3}$ Since it has the potential advantage of not traversing the biliary stricture, it may play a role in the management of hilar $\mathrm{MBO}$ as well. ${ }^{4}$

\footnotetext{
Received: June 1, 2018 Revised: June 26, 2018

Accepted: June 27, 2018

Correspondence: Yousuke Nakai

Department of Gastroenterology, Graduate School of Medicine, The University of Tokyo, 7-3-1 Hongo Bunkyo-ku, Tokyo 113-8655, Japan

Tel: +81-3-3815-5411, Fax: +81-3-5800-9801, E-mail: ynakai-tky@umin.ac.jp ORCID: https://orcid.org/0000-0001-7411-1385
}

(c) This is an Open Access article distributed under the terms of the Creative Commons Attribution Non-Commercial License (http://creativecommons.org/ licenses/by-nc/3.0) which permits unrestricted non-commercial use, distribution, and reproduction in any medium, provided the original work is properly cited.
However, data on EUS-BD for hilar MBO are still limited. In this review article, we will overview EUS-BD for hilar MBO.

\section{CURRENT MANAGEMENT OF UNRESECTABLE HILAR MBO}

In unresectable hilar $\mathrm{MBO}$, biliary drainage can be achieved either by EBD or PTBD. Although a systematic review ${ }^{5}$ showed a better success rate of PTBD, EBD is the current standard of care because PTBD impairs the quality of life in general whereas EBD does not. There are some options for endoscopic management of hilar MBO: Plastic stent (PS) vs. $\mathrm{MS}^{6,7}$ and unilateral vs. bilateral stenting.

MS is shown to have longer stent patency than PS in randomized controlled trials (RCTs). ${ }^{6,7}$ Some reports have demonstrated the association of liver volume with adequate biliary drainage. One study ${ }^{10}$ showed that $33 \%$ of the liver volume should be drained in cases that have preserved liver function to obtain adequate biliary drainage, whereas $50 \%$ of the liver volume should be drained in those with impaired liver function. In another study, longer survival rates were observed in cases of hilar $\mathrm{MBO}$ after draining $\geq 50 \%$ of the liver 
volume. $^{11}$ To drain $\geq 50 \%$ the liver volume, bilateral biliary drainage is necessary in most cases. A recent Korean $\mathrm{RCT}^{12}$ clearly demonstrated the superiority of bilateral MS placement over unilateral MS placement. Bilateral MS placement showed a longer duration of stent patency (252 days vs. 139 days, $p<0.01)$ and statistically non-significant but clinically significant differences in survival (270 days vs. 178 days, $p=0.053$ ).

The recent development of MS suitable for hilar stenting via a thin delivery system allows easy bilateral stent placement, either by using a stent-in-stent method ${ }^{13,14}$ or a sideby-side method. ${ }^{15}$ These MS also allow re-interventions after recurrent biliary obstruction (RBO) following bilateral stent placement; ${ }^{16}$ nevertheless, the procedure can be technically difficult or even impossible. When endoscopic re-intervention fails, PTBD may be necessary to relieve jaundice or cholangitis, which impairs the quality of life due to the indwelling drainage tube. Technical and clinical hurdles of transpapillary multiple MS placement for hilar MBO are caused by the complexity of the stent configuration at the hepatic hilum. To overcome the limitations of conventional approaches such as EBD and/or PTBD, another novel approach for hilar MBO has been long awaited.

\section{INDICATIONS OF EUS-BD FOR HILAR MBO}

EUS-BD is being increasingly utilized in the management of $\mathrm{MBO}$ in cases of failed or difficult endoscopic retrograde cholangiopancreatography (ERCP). In addition to obtaining biliary access after failed ERCP, EUS-BD does not traverse the biliary stricture, which may provide an advantage in the management of hilar MBO. There are two approaches used by EUS-BD, intrahepatic and extrahepatic, but the intrahepatic approach is mandatory for hilar MBO.

Indications and contraindications of EUS-BD for hilar $\mathrm{MBO}$ are shown in Table 1 . Theoretically, EUS-BD can be indicated for any hilar $\mathrm{MBO}$ but the current indications are failed ERCP, surgically altered anatomy, and failed re-interventions for occlusion of transpapillary placed stents. Contraindications are severe coagulopathy, massive ascites, intervening vessels, and unstable conditions unfit for endoscopic procedures. In such cases, EUS-BD might have higher risks of morbidity or mortality due to complications such as bleeding, bile leak, and stent migration. Furthermore, despite reports of a high technical success rate and acceptable adverse event rate, expertise is necessary for EUS-BD as dedicated devices for EUS-BD are currently limited.

\section{TECHNIQUES OF EUS-BD FOR HILAR MBO}

EUS-guided hepaticogastrostomy (EUS-HGS) is one of the most common EUS-BD procedures via an intrahepatic approach. ${ }^{17}$ In EUS-HGS, biliary access to segment 2 or 3 is established via the cardia or lesser curvature of the stomach under EUS guidance, and a stent is placed from $\mathrm{B} 2$ or $\mathrm{B} 3$ to the stomach. In hilar $\mathrm{MBO}$, therefore, biliary drainage of the left biliary system alone is achieved by EUS-HGS, leaving the right biliary system undrained with potential risks of inadequate biliary drainage or segmental cholangitis.

As shown in transpapillary stenting, bilateral drainage can potentially lead to better clinical outcomes for hilar MBO. The approaches to obtain bilateral drainage with EUS-BD include a bridging method, EUS-guided hepaticoduodenostomy (EUS-HDS), and a combined EUS and ERCP approach (Fig. 1).

The bridging method ${ }^{18}$ employs a left intrahepatic bile duct (IHBD) access similar to conventional EUS-HGS. After obtaining biliary access from the stomach to the left IHBD using a 19-gauge fine needle aspiration needle and a guidewire, the needle is replaced by a standard catheter and a guidewire is advanced through the hilar stricture into the right IHBD. In difficult cases, a steerable catheter and a hydrophilic guidewire are helpful to pass the hilar stricture. An uncovered bridging MS with a thin delivery system is placed across the hilar stricture, followed by a covered MS placement from the left IHBD to the stomach, as seen with conventional EUS-HGS. During this bridging method, guidewire passage or stent deployment to the right biliary system through the hilar stricture can be technically challenging depending on the angle of left and right hepatic duct confluence. In technically difficult cases, a prolonged procedure time can increase the risk of bile leak and sequential bridging stent placement can be an option. A conventional HGS stent is placed in the left IHBD in the first

Table 1. Current Indications and Contraindications of Endoscopic Ultrasound-Guided Biliary Drainage for Hilar Malignant Biliary Obstruction

\begin{tabular}{l}
\hline Indications \\
Failed ERCP \\
Surgically altered anatomy i.e., Roux-en-Y reconstruction \\
Failed re-intervention for transpapillary stent occlusion \\
Contraindications \\
Severe coagulopathy \\
Massive ascites \\
Intervening vessels including collateral vessels \\
Unstable conditions unfit for endoscopic procedures \\
\hline ERCP, endoscopic retrograde cholangiopancreatography.
\end{tabular}


session and after fistula maturation of the HGS, a bridging stent placement can be attempted by cannulating through the HGS stent (Fig. 2).

EUS-HDS ${ }^{18,19}$ employs a right IHBD access from the duodenum, which is a complement of EUS-HGS to the left IHBD. However, EUS-HDS procedures are performed only in a few expert centers and therefore, reports are limited. Ogura et al. ${ }^{18}$ reported a locking method with a combination of uncovered and covered MSs to prevent stent migration but the use of a PS dedicated to EUS- $\mathrm{BD}^{20}$ was also reported. Given the limited number of reports, the best technique of EUS-HDS has not been established thus far.

In high-grade hilar MBO, a combined EUS and ERCP approach proposed by Park ${ }^{21}$ can be a treatment option. In this approach, EUS-HGS to the left IHBD and transpapillary stenting to the right IHBD are performed (Fig. 3). This approach is feasible due to two anatomical reasons. First, as observed with resectable hilar $\mathrm{MBO}$, the left hepatic duct is longer than the right hepatic duct, allowing drainage of the whole left biliary system by a single EUS-HGS stent. Second, the right IHBD is more prone to cancer invasion especially in cases with gallbladder cancer, necessitating multiple stenting of the right biliary system. Although multiple stenting in EUS-BD is theoretically possible, transpapillary multiple stent placement is more established. Therefore, a combination of simple EUSHGS in the left IHBD and multiple stenting in the right IHBD can achieve $>50 \%$ biliary drainage with technical feasibility.

\section{CLINICAL OUTCOMES OF EUS-BD FOR HILAR MBO}

Table 2 summarized data on EUS-BD for hilar MBO. ${ }^{18-20,22-29}$ The overall technical success rate was $98 \%$ and the overall
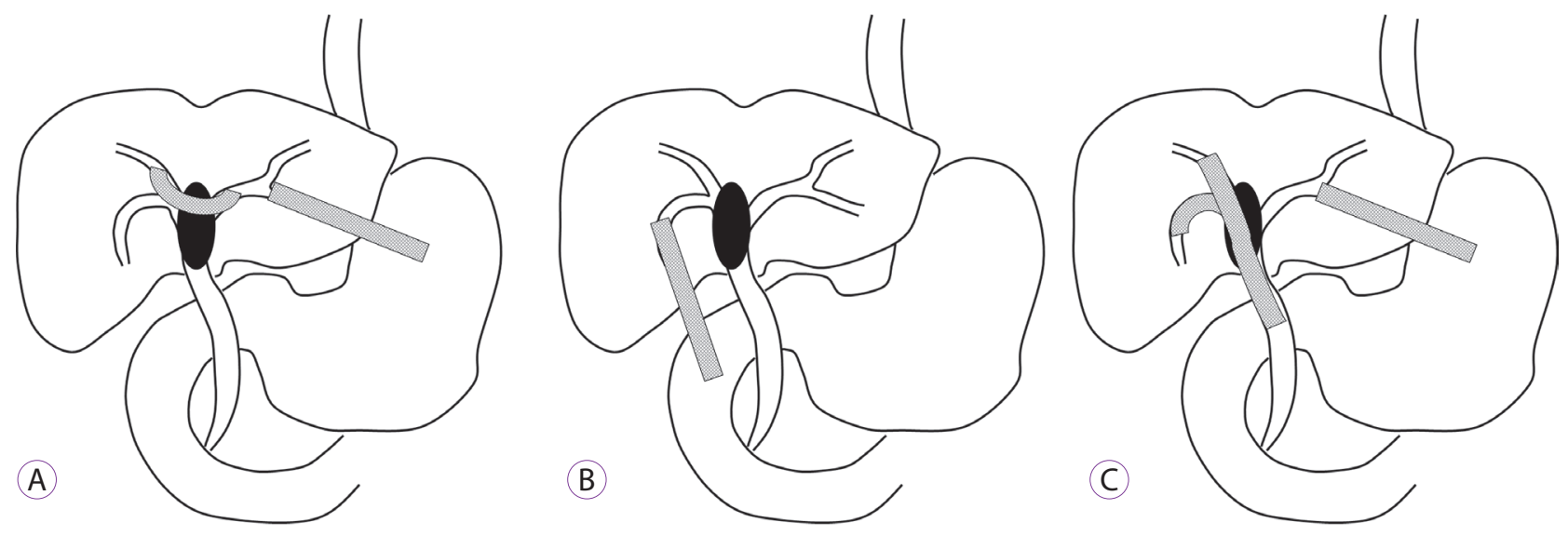

Fig. 1. Techniques of bilateral endoscopic ultrasound-guided biliary drainage. (A) Bridging method. (B) Endoscopic ultrasound-guided hepaticoduodenostomy. (C) Combined endoscopic ultrasound-guided hepaticogastrostomy and transpapillary stenting.
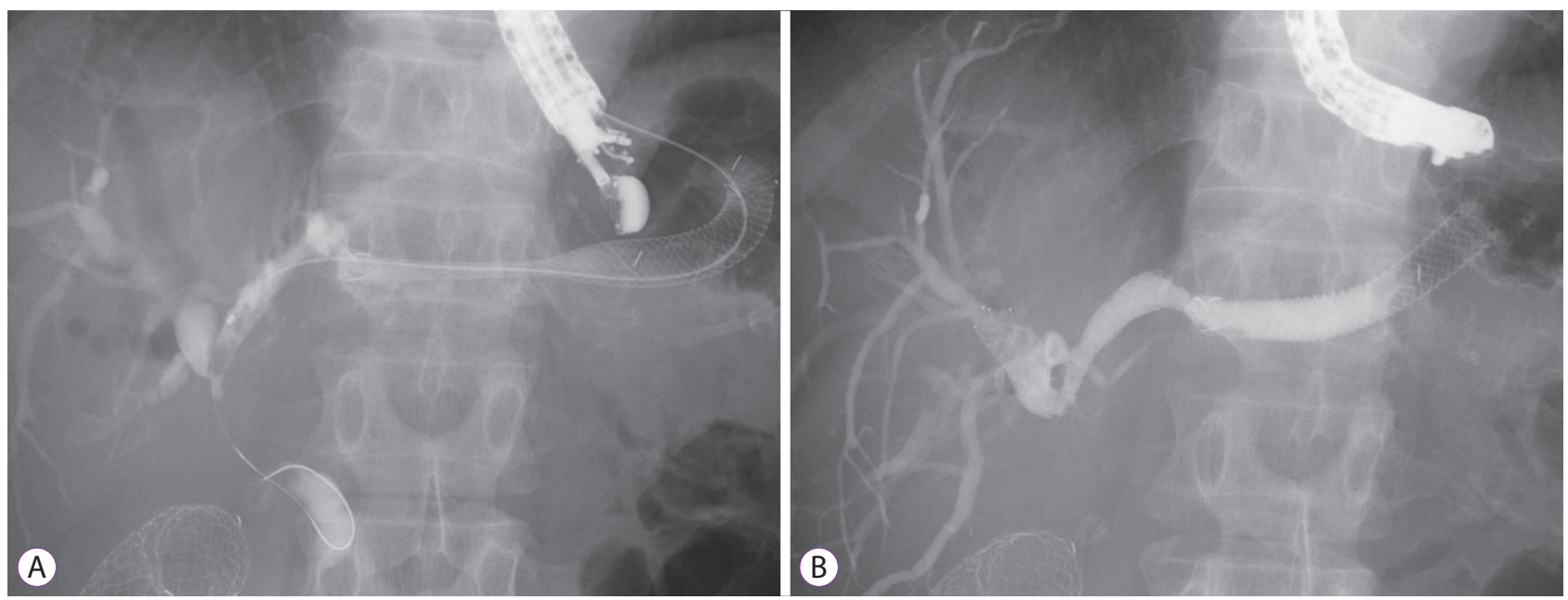

Fig. 2. Bridging method. (A) Endoscopic ultrasound-guided hepaticogastrostomy was performed during the first session. (B) A bridging stent was placed during the second session. 

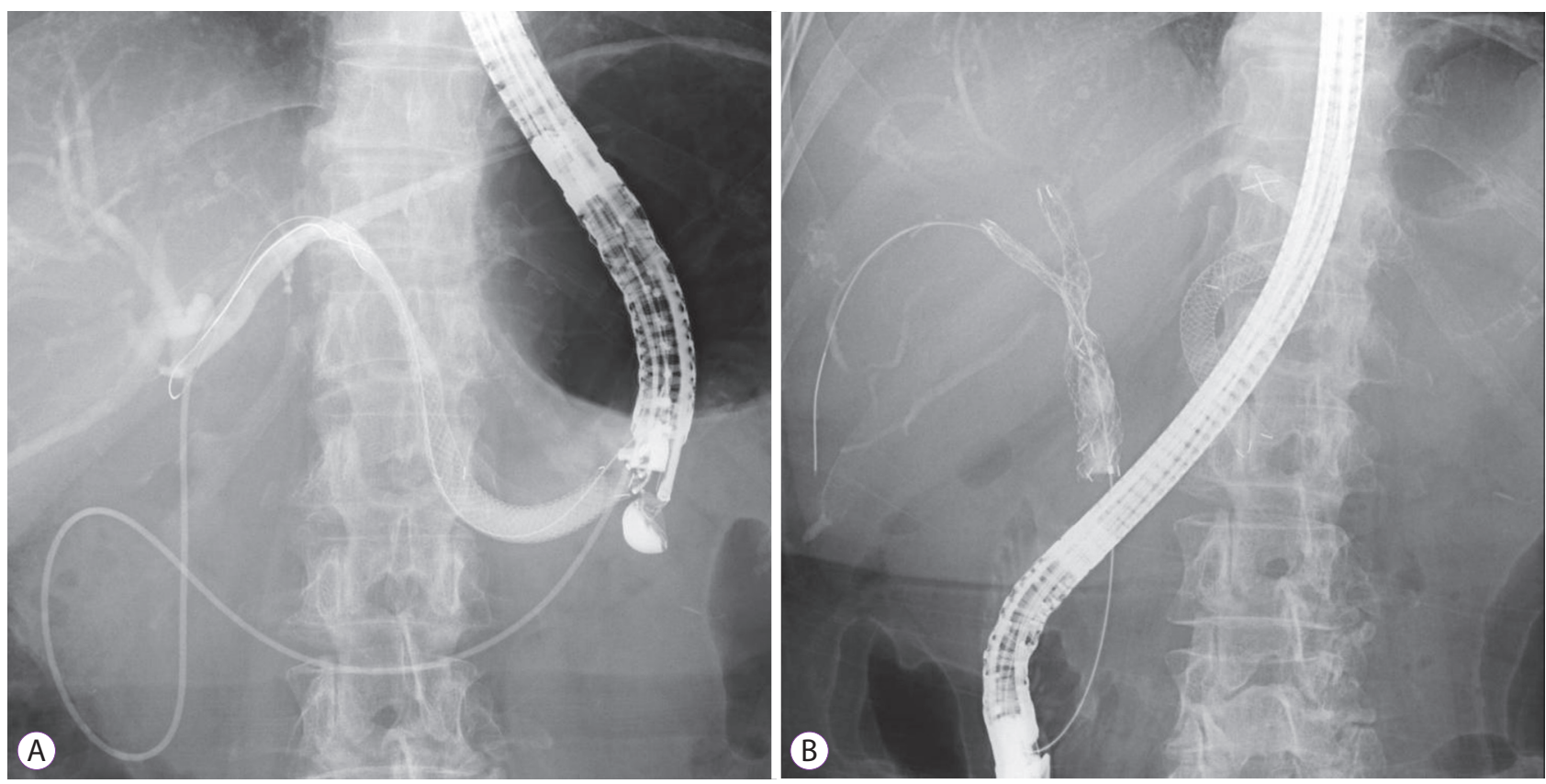

Fig. 3. Combined endoscopic ultrasound-guided hepaticogastrostomy and transpapillary stenting. (A) Endoscopic ultrasound-guided hepaticogastrostomy was performed during the first session. (B) Transpapillary multiple stent-in-stent placement was performed during the second session.

Table 2. Data on Endoscopic Ultrasound-Guided Biliary Drainage for Hilar Malignant Biliary Obstruction

\begin{tabular}{|c|c|c|c|c|c|c|c|}
\hline Study & $n$ & Initial/Rescue & Stent & Drainage method & Technical success & Clinical success & Adverse events \\
\hline Bories et al. $(2007)^{22}$ & 4 & Initial & PS & HGS & 4 & 4 & 1 stent clogging \\
\hline Ogura et al. $(2014)^{23}$ & 1 & Initial & UMS+CMS & Bridging & 1 & N/A & N/A \\
\hline Ogura et al. $(2015)^{18}$ & 11 & $\begin{array}{l}\text { Initial/ } \\
\text { Rescue }\end{array}$ & UMS+CMS & $\begin{array}{l}4 \text { HDS, } \\
7 \text { Bridging }\end{array}$ & 11 & N/A & 0 \\
\hline $\begin{array}{l}\text { Prachayakul et al. } \\
\qquad(2015)^{24}\end{array}$ & 1 & Initial & UMS+CMS & Bridging & 1 & 1 & 0 \\
\hline $\begin{array}{l}\text { Moryoussef et al. } \\
(2017)^{25}\end{array}$ & 18 & Initial & UMS+CMS & $\begin{array}{l}14 \text { HGS, } \\
3 \text { Bridging }\end{array}$ & 17 & 13 & 3 \\
\hline Park et al. $(2010)^{26}$ & 3 & Rescue & CMS & HGS & 3 & 3 & 0 \\
\hline Park et al. $(2013)^{19}$ & 2 & Rescue & CMS & HDS & 2 & 2 & 0 \\
\hline $\begin{array}{l}\text { Minaga et al. } \\
\qquad(2017)^{27}\end{array}$ & 30 & Rescue & CMS or PS & $\begin{array}{l}28 \mathrm{HGS} \text {, } \\
2 \mathrm{HDS}\end{array}$ & 29 & 22 & 3 bile peritonitis \\
\hline Ogura et al. $(2017)^{28}$ & 10 & Rescue & CMS & $\begin{array}{l}8 \text { HGS, } \\
2 \text { HDS }\end{array}$ & 10 & 9 & 0 \\
\hline Kanno et al. $(2017)^{29}$ & 7 & Rescue & CMS & HGS & 7 & 4 & 0 \\
\hline Mukai et al. $(2017)^{20}$ & 1 & Rescue & PS & HDS & 1 & N/A & 0 \\
\hline Overall & 88 & & & & $\begin{array}{c}98 \% \\
(86 / 88)\end{array}$ & $\begin{array}{c}77 \% \\
(58 / 75)\end{array}$ & $\begin{array}{c}8 \% \\
(7 / 87)\end{array}$ \\
\hline
\end{tabular}

CMS, covered metal stent; HDS, hepaticoduodenostomy; HGS, hepaticogastrostomy; N/A, not available; PS, plastic stent; UMS, uncovered metal stent.

adverse event rate was $8 \%$. However, the overall clinical success rate was $77 \%$, which was lower than previously reported in a systematic review of EUS-BD. ${ }^{30}$ Clinical outcomes were comparable between the initial EUS-BD procedure and the rescue EUS-BD procedure after failed transpapillary drainage. However, the number of cases was too small and the procedures were performed only by experts. Therefore, publication bias was possible especially with respect to adverse events. A 
Table 3. Advantages and Disadvantages of EUS-BD

\begin{tabular}{|c|c|c|c|}
\hline & EUS-BD & EBD & PTBD \\
\hline Advantage & $\begin{array}{l}\text { A single step internal drainage } \\
\text { Simplicity at the hilum: possible longer patency }\end{array}$ & Long term data available & $\begin{array}{l}\text { High technical success rate } \\
\text { Possible tube rinse for clogging }\end{array}$ \\
\hline Disadvantage & $\begin{array}{l}\text { No long term data } \\
\text { Special technique necessary for right IHBD } \\
\text { approach } \\
\text { Contraindications: ascites, coagulopathy } \\
\text { Chance of bile leak, stent migration }\end{array}$ & $\begin{array}{l}\text { Technical difficulty for multi- } \\
\text { ple stenting } \\
\text { Complexity at the hilum } \\
\text { Chance of Post-ERCP pancre- } \\
\text { atitis }\end{array}$ & $\begin{array}{l}\text { Impaired QOL } \\
\text { High AE rate and re-interven- } \\
\text { tion rate } \\
\text { Contraindications: ascites, co- } \\
\text { agulopathy }\end{array}$ \\
\hline
\end{tabular}

$\mathrm{AE}$, adverse event; EBD, endoscopic transpapillary biliary drainage; ERCP, endoscopic retrograde cholangiopancreatography; EUS-BD, endoscopic ultrasound-guided biliary drainage; IHBD, intrahepatic bile duct; PTBD, percutaneous transhepatic biliary drainage; QOL, quality of life.

relatively low clinical success rate suggests that appropriate biliary drainage for unresectable hilar MBO is difficult in any approach: ERCP, EUS, or PTBD. The available literature was focused on short-term outcomes and long-term outcomes such as RBO and its re-interventions were not investigated. Future studies should be focused on patient selection or on treatment selection for better management of hilar $\mathrm{MBO}$.

\section{EUS-BD IN COMPARISON WITH TRANSPAPILLARY BILIARY STENTING AND PTBD}

Transpapillary stenting is still the standard of care for unresectable hilar $\mathrm{MBO}$, and $\mathrm{PTBD}$ is often a rescue procedure for failed endoscopic management. As described above, EUS-BD has a definite role in the management of hilar MBO. The advantages and disadvantages are summarized in Table 3. Overall, EUS-BD has a common advantage of both transpapillary stenting and PTBD, namely, a single session internal drainage without crossing the biliary stricture. Internal drainage maintains the quality of life and drainage without crossing the stricture potentially allows longer stent patency.

\section{LIMITATIONS OF EUS-BD}

First of all, the number of reported cases is small. Although the rate of technical success is high, most studies were reported by experts and publication bias may exist. Theoretically, EUS-BD provides better stent patency but long-term outcomes are unclear. Given the improved survival in cases of biliary malignancy, many patients with unresectable hilar $\mathrm{MBO}$ need re-intervention for RBO. Endoscopic re-interventions through the EUS-BD route are often possible but PTBD is sometimes necessary to control cholangitis after complex biliary drainage procedures. In addition, the rate of adverse events was only $8 \%$ in our review but the intrahepatic approach reportedly had a higher adverse event rate compared to the extrahepatic approach. ${ }^{31}$ Finally, technical expertise for performing EUS-BD is not always available in most centers. In such situations, if urgent drainage for cholangitis is necessary, a PTBD can be temporarily placed and conversion from PTBD to EUS-BD can be performed at a later stage. ${ }^{32}$ Overall, the evidence regarding these issues is limited and further investigation is warranted.

\section{CONCLUSIONS}

In conclusion, EUS-BD can be a promising treatment option for unresectable hilar MBO, both as the initial and the rescue procedure. Standardization of procedures as well as development of dedicated devices are necessary to establish the role of EUS-BD in the management of hilar MBO. Future RCTs comparing EUS-BD with EBD or PTBD are warranted to confirm the role of EUS-BD for managing hilar MBO.

Conflicts of Interest

The authors have no financial conflicts of interest.

\section{REFERENCES}

1. Moon JH, Rerknimitr R, Kogure H, Nakai Y, Isayama H. Topic controversies in the endoscopic management of malignant hilar strictures using metal stent: side-by-side versus stent-in-stent techniques. J Hepatobiliary Pancreat Sci 2015;22:650-656.

2. Nakai $\mathrm{Y}$, Isayama $\mathrm{H}$, Yamamoto $\mathrm{N}$, et al. Indications for endoscopic ultrasonography (EUS)-guided biliary intervention: does EUS always come after failed endoscopic retrograde cholangiopancreatography? Dig Endosc 2017;29:218-225.

3. Minaga K, Kitano M. Recent advances in endoscopic ultrasound-guided biliary drainage. Dig Endosc 2018;30:38-47.

4. Nakai Y, Isayama H, Matsubara S, Koike K. Conversion of transpapillary drainage to endoscopic ultrasound-guided hepaticogastrostomy and gallbladder drainage in a case of malignant biliary obstruction with 
recurrent cholangitis and cholecystitis (with videos). Endosc Ultrasound 2017;6:205-207.

5. Moole H, Dharmapuri S, Duvvuri A, et al. Endoscopic versus percutaneous biliary drainage in palliation of advanced malignant hilar obstruction: a meta-analysis and systematic review. Can J Gastroenterol Hepatol 2016;2016:4726078.

6. Sangchan A, Kongkasame W, Pugkhem A, Jenwitheesuk K, Mairiang P. Efficacy of metal and plastic stents in unresectable complex hilar cholangiocarcinoma: a randomized controlled trial. Gastrointest Endosc 2012;76:93-99.

7. Mukai T, Yasuda I, Nakashima M, et al. Metallic stents are more efficacious than plastic stents in unresectable malignant hilar biliary strictures: a randomized controlled trial. J Hepatobiliary Pancreat Sci 2013;20:214-222.

8. De Palma GD, Galloro G, Siciliano S, Iovino P, Catanzano C. Unilateral versus bilateral endoscopic hepatic duct drainage in patients with malignant hilar biliary obstruction: results of a prospective, randomized, and controlled study. Gastrointest Endosc 2001;53:547-553.

9. Yasuda I, Mukai T, Moriwaki H. Unilateral versus bilateral endoscopic biliary stenting for malignant hilar biliary strictures. Dig Endosc 2013;25 Suppl 2:81-85.

10. Takahashi E, Fukasawa M, Sato T, et al. Biliary drainage strategy of unresectable malignant hilar strictures by computed tomography volumetry. World J Gastroenterol 2015;21:4946-4953.

11. Vienne A, Hobeika E, Gouya H, et al. Prediction of drainage effectiveness during endoscopic stenting of malignant hilar strictures: the role of liver volume assessment. Gastrointest Endosc 2010;72:728-735.

12. Lee TH, Kim TH, Moon JH, et al. Bilateral versus unilateral placement of metal stents for inoperable high-grade malignant hilar biliary strictures: a multicenter, prospective, randomized study (with video). Gastrointest Endosc 2017;86:817-827.

13. Lee TH, Moon JH, Kim JH, et al. Primary and revision efficacy of crosswired metallic stents for endoscopic bilateral stent-in-stent placement in malignant hilar biliary strictures. Endoscopy 2013;45:106-113.

14. Kogure H, Isayama $H$, Nakai $Y$, et al. High single-session success rate of endoscopic bilateral stent-in-stent placement with modified large cell Niti-S stents for malignant hilar biliary obstruction. Dig Endosc 2014;26:93-99.

15. Lee TH, Park DH, Lee SS, et al. Technical feasibility and revision efficacy of the sequential deployment of endoscopic bilateral side-by-side metal stents for malignant hilar biliary strictures: a multicenter prospective study. Dig Dis Sci 2013;58:547-555.

16. Lee TH, Moon JH, Choi HJ, et al. Third metal stent for revision of malignant hilar biliary strictures. Endoscopy 2016;48:1129-1133.

17. Nakai $\mathrm{Y}$, Isayama $\mathrm{H}$, Yamamoto $\mathrm{N}$, et al. Safety and effectiveness of a long, partially covered metal stent for endoscopic ultrasound-guided hepaticogastrostomy in patients with malignant biliary obstruction. Endoscopy 2016;48:1125-1128.
18. Ogura T, Sano T, Onda S, et al. Endoscopic ultrasound-guided biliary drainage for right hepatic bile duct obstruction: novel technical tips. Endoscopy 2015;47:72-75.

19. Park SJ, Choi JH, Park DH, et al. Expanding indication: EUS-guided hepaticoduodenostomy for isolated right intrahepatic duct obstruction (with video). Gastrointest Endosc 2013;78:374-380.

20. Mukai S, Itoi T, Tsuchiya T, Tanaka R, Tonozuka R. EUS-guided right hepatic bile duct drainage in complicated hilar stricture. Gastrointest Endosc 2017;85:256-257.

21. Park DH. Endoscopic ultrasound-guided biliary drainage of hilar biliary obstruction. J Hepatobiliary Pancreat Sci 2015;22:664-668.

22. Bories E, Pesenti C, Caillol F, Lopes C, Giovannini M. Transgastric endoscopic ultrasonography-guided biliary drainage: results of a pilot study. Endoscopy 2007;39:287-291.

23. Ogura T, Masuda D, Imoto A, Umegaki E, Higuchi K. EUS-guided hepaticogastrostomy for hepatic hilar obstruction. Endoscopy 2014;46 Suppl 1 UCTN:E32-E33.

24. Prachayakul V, Aswakul P. Endoscopic ultrasound-guided biliary drainage: bilateral systems drainage via left duct approach. World J Gastroenterol 2015;21:10045-10048.

25. Moryoussef F, Sportes A, Leblanc S, Bachet JB, Chaussade S, Prat F. Is EUS-guided drainage a suitable alternative technique in case of proximal biliary obstruction? Therap Adv Gastroenterol 2017;10:537-544.

26. Park DH, Song TJ, Eum J, et al. EUS-guided hepaticogastrostomy with a fully covered metal stent as the biliary diversion technique for an occluded biliary metal stent after a failed ERCP (with videos). Gastrointest Endosc 2010;71:413-419.

27. Minaga K, Takenaka M, Kitano M, et al. Rescue EUS-guided intrahepatic biliary drainage for malignant hilar biliary stricture after failed transpapillary re-intervention. Surg Endosc 2017;31:4764-4772.

28. Ogura T, Onda S, Takagi W, et al. Clinical utility of endoscopic ultrasound-guided biliary drainage as a rescue of re-intervention procedure for high-grade hilar stricture. J Gastroenterol Hepatol 2017;32:163-168.

29. Kanno Y, Ito K, Koshita S, et al. EUS-guided biliary drainage for malignant perihilar biliary strictures after further transpapillary intervention has been judged to be impossible or ineffective. Intern Med 2017;56:3145-3151.

30. Wang K, Zhu J, Xing L, Wang Y, Jin Z, Li Z. Assessment of efficacy and safety of EUS-guided biliary drainage: a systematic review. Gastrointest Endosc 2016;83:1218-1227.

31. Dhir V, Artifon EL, Gupta K, et al. Multicenter study on endoscopic ultrasound-guided expandable biliary metal stent placement: choice of access route, direction of stent insertion, and drainage route. Dig Endosc 2014;26:430-435

32. Paik WH, Lee NK, Nakai Y, et al. Conversion of external percutaneous transhepatic biliary drainage to endoscopic ultrasound-guided hepaticogastrostomy after failed standard internal stenting for malignant biliary obstruction. Endoscopy 2017;49:544-548. 